\title{
МИНЕРАЛОГИЧЕСКИЙ СОСТАВ МЫТОГО СУШЕНОГО КОНЦЕНТРАТА КЫЗЫЛКУМОВ И ЕГО ПЕРЕРАБОТКА В ПРОСТОЙ СУПЕРФОСФАТ
}

\author{
Х.А. Отабоев, Д. Ш. Шеркузиев, О.А. Бадалова, Р. Раджабов, \\ Ш. С. Намазов", А. Р. Сейтназаров
}

Институт общей и неорганической химии Академии наук Республики Узбекистан, ул. Мирзо-Улугбек, 77а, Таикент, Узбекистан, 100170.E-mail: diana-ye@yandex.com.

\begin{abstract}
Проанализированы различные виды фосфатных минералов апатитовой группы. Фосфатное вещество фосфоритов кроме фторапатита, может быть представлено, фторкарбонатапатитом - франколитом либо курскитом. Наибольшим содержанием фосфора обладает фторапатит, а наименьшим курскит. По величине параметров элементарной ячейки $\left(a_{o}=9,33 A^{\circ}\right)$ фосфатным минералом зернистых фосфоритов является франколит.

Рентгенографическими и химическими методами исследования изучен минералогический состав мытого сушеного кониентрата - зернистого типа фосфоритов Центральных Кызылкумов. Установлено, что главным фосфатным минералом зернистых фосфоритов Кызылкумов является франколит. В качестве примесей присутствуют кальиит, доломит, гипс, квари, кальииевый силикат и др. Рассчитана норма серной кислоты для разложения мытого сушеного концентрата $\left(25,75 \% \mathrm{P}_{2} \mathrm{O}_{5}\right)$ с получением простого суперфосфата (не менее $17 \% \mathrm{P}_{2} \mathrm{O}_{5}$ ). Отличительной особенностью предлагаемого поточного способа перед классической (камерной) является то, что весь производственный иикл обработки природного фосфата осуществляется в две стадии. На 1-ой стадии фосфатное сырьё обрабатывается стехиометрическим расходом концентрированной серной кислотой (не менее 93 \%), в условиях полного разложения мытого сушеного концентрата с образованием фосфорной кислоты и кристаллов ангидрита (сульфат кальиия). При этом температура реакиии составляет $130{ }^{\circ} \mathrm{C}$. На второй стадии, образовавшийся кониентрированный раствор фосфорной кислоты в смеси с серной участвует в реакции с дополнительным вводимым количеством мытого сушеного концентрата, что является основой механизма химического образования монокальцийфосфата и гранулирования суперфосфатной массы. По сравнению с классической схемой, из проиесса исключаются стадии складского созревания, аммонизации и сушки продукта.
\end{abstract}

Ключевые слова: мытый сушеный концентрат, рентгенографическое исследование, химический и минералогический составы, серная кислота, разложение, простой суперфосфат.

\section{MINERALOGICAL COMPOSITION OF KYZYLKUM WASHED DRY CONCENTRATE AND ITS PROCESSING INTO SIMPLE SUPERPHOSPHATE}

\author{
Kh.A. Otaboev, D.Sh. Sherkuziev, O.A. Badalova, R. Radjabov, \\ Sh.S. Namazov*, A. R. Seytnazarov \\ Institute of General and Inorganic Chemistry, Academy of Sciences of Uzbekistan, Mirzo-Ulugbek str., 77a, \\ Tashkent, 100170, Uzbekistan.E-mail: diana-ye@yandex.com.
}


The various types of phosphate minerals of the apatite group have been analyzed. The phosphate substance of phosphorites except fluorapatite, can be represented by fuorocarbon apatite - francolite or kurskite. The highest phosphorus content is found in fluorapatite, and the lowest in kurskite. In terms of the unit cell parameters $\left(a^{o}=9,33 A^{\circ}\right)$, the phosphate mineral of granular phosphorites of the Kyzylkum desert is francolite.

The mineralogical composition of the washed dried concentrate, a granular type of phosphorites of the Central Kyzyl Kum, was studied by X-ray and chemical methods of research. It has been established that the main phosphate mineral of granular phosphorites of the Kyzyl Kum is francolite. Calcite, dolomite, gypsum, quartz, calcium silicate, etc. are present as gangue. The rate of sulfuric acid for the decomposition of washed dried concentrate $\left(25,75 \% \mathrm{P}_{2} \mathrm{O}_{5}\right)$ in terms of obtaining simple superphosphate (at least $\left.17 \% \mathrm{P}_{2} \mathrm{O}_{5}\right)$ has been calculated. A distinctive feature of the proposed in-line method over the classical (chamber) is that the entire production cycle of natural phosphate processing is carried out in two stages. At the first stage, the phosphate raw material is treated with a stoichiometric consumption of concentrated sulfuric acid (at least $93 \%$ ), under conditions of complete decomposition of the washed dried concentrate with the formation of phosphoric acid and anhydrite crystals (calcium sulfate). The reaction temperature is $130^{\circ} \mathrm{C}$. At the second stage, the resulting concentrated solution of phosphoric acid in a mixture with sulfuric acid participates in the reaction with an additional introduced amount of washed dried concentrate, which is the basis of the mechanism of chemical formation of monocalcium phosphate and granulation of superphosphate mass. On comparison to the conventional flowsheet, the process excludes the stages of warehouse maturation, ammonization and drying of the product.

Keywords: washed dried concentrate, X-ray diffraction, chemical and mineralogical composition, sulfuric acid, decomposition, simple superphosphate.

\section{Введение}

Фосфатное сырье необходимо для производства минеральных удобрений, химической и металлургической промышленности, получения флотореагентов, моющих средств, в качестве минеральной подкормки скота и птицы, а также для других целей [1].

Фосфатная промышленность опирается на мощнейшую сырьевую базу. Выявленные мировые запасы фосфатных руд учтены по 76 странам и оцениваются в 70587,4 млн. т $\mathrm{P}_{2} \mathrm{O}_{5}$, в том числе 65328,4 млн. т фосфоритовых и 5259 млн. т апатитовых руд [2]. В десяти странах (США, Марокко, Китай, Россия, Мексика, Казахстан, Перу, ЮАР, Западная Сахара и Тунис) сконцентрировано 61015,4 млн. т $\mathrm{P}_{2} \mathrm{O}_{5}$, что составляет 87 \% общемировых запасов. Значительные залежи фосфатных пород выявлены на дне морей и океанов, главным образом на шельфах. Они оценены в 7271 млн. т $\mathrm{P}_{2} \mathrm{O}_{5}$ (примерно $12 \%$ от запасов на суше).

Если говорить о странах, то безусловным лидером является Марокко, за которым следует США, Китай, Россия и Казахстан [3]. Апатитовые руды составляют около 1/5 от мировых ресурсов фосфатного сырья. Наибольшими запасами обладают Россия, ЮАР, Уганда, Китай, Бразилия и Вьетнам.

Страны, производящие фосфатное сырьё (в 2001 г. число их составило 31), можно условно разделить на три группы [4]. Первая группа (основные продуценты) - США, Марокко, Китай и Россия (более 10 млн. т/год), на долю которых приходится
67,7 \% всего мирового производства; вторая группа представлена 10 странами (Тунис, Иордания, Бразилия, Израиль, ЮАР, Сирия, Сенегал, Австралия, Индия и Того), на долю которых приходится $26 \%$ мировой продукции; третья - 17 стран - Казахстан, Египет, Алжир, Мексика, Канада, Финляндия, Вьетнам, Остров Рождества, Венесуэла, Ирак, Науру, Узбекистан, КНДР, Зимбабве, Колумбия, Шри-Ланка и Перу, производящие 6,3 \% фосфатного сырья. Предполагается, что к 2050 г ежегодное производство и потребление фосфатного сырья составят около 70 млн. т $\mathrm{P}_{2} \mathrm{O}_{5}$ (220 млн. т фосфатного сырья).

Согласно принятой классификации, по содержанию полезного компонента руды подразделяются на очень бедные $\left(2-8 \% \mathrm{P}_{2} \mathrm{O}_{5}\right)$, бедные (8-18\% $\mathrm{P}_{2} \mathrm{O}_{5}$ ), средние $\left(18-28 \% \mathrm{P}_{2} \mathrm{O}_{5}\right)$ и богатые (свыше $28 \% \mathrm{P}_{2} \mathrm{O}_{5}$ ). Чем выше содержание $\mathrm{P}_{2} \mathrm{O}_{5}$ в сырье, тем лучше экономические показатели его переработки. Самым лучшим в мире фосфатным сырьем является Хибинский апатитовый концентрат (Россия). Он содержит $39,54 \% \mathrm{P}_{2} \mathrm{O}_{5}$. Только для Хибинского концентрата и аналогичного ему зарубежного фосфатного сырья Хурибга 80-82 TPL, Бу Краа 80 TPL (Марокко), Науру 84 BPL существуют технологии получения из него любых видов фосфорсодержащих удобрений с приемлемыми технико-экономическими показателями.

(Примечание: за рубежом основной характеристикой сырьевых фосфатных продуктов принято считать процентное содержание в них трикальцийфосфата $\mathrm{Ca}_{3}\left(\mathrm{PO}_{4}\right)_{2}$ (английское $\mathrm{BPL}$, француз- 
ское TPL; $1 \%$ BPL соответствует 0,4576 \% $\mathrm{P}_{2} \mathrm{O}_{5}$, или $0,1997 \%$ P, и, наоборот, $1 \% \mathrm{P}_{2} \mathrm{O}_{5}-2,185 \% \mathrm{BPL}$, или $0,436 \%$ P) [5].

Однако запасы качественных руд неуклонно истощаются, наблюдается тенденция вовлечения в промышленную переработку более бедных фосфоритовых (15-20\% $\left.\mathrm{P}_{2} \mathrm{O}_{5}\right)$ и очень бедных апатитовых руд (4-8\% $\mathrm{P}_{2} \mathrm{O}_{5}$ ). В связи с этим решающим фактором в фосфатной промышленности является успешное обогащение бедных фосфатных, особенно фосфатно-карбонатных руд, запасы которых составляют две трети мировых запасов [6]. Другой важной технической задачей является разработка и промышленная реализация технологических процессов производства фосфорсодержащих удобрений из низкосортного фосфатного сырья.

В Узбекистане основным фосфатным сырьём являются зернистые фосфориты Кызылкумского месторождения. Запасы фосфатного сырья в недрах до глубины 50 м, то есть пригодных для открытой разработки, утверждены по трем месторождениям: Джерой-Сардара, Северный Джетымтау и Караката. Утвержденные запасы руды составляет 384413 тыс. т (среднее содержание $\mathrm{P}_{2} \mathrm{O}_{5}$ в руде $-19,5 \%$ ) или 74960 тыс. т $\mathrm{P}_{2} \mathrm{O}_{5}$ [4].

Фосфоритная руда имеет следующий средний минеральный состав, \%: франколит - 56,0; кальцит - 26,5; кварц - 7,5-8,0; гидрослюдистые минералы и полевые шпаты - 4,0-4,5; гипс $-3,5$; гетит 1,0 ; цеолит менее 1 ; органическое вещество - около 0,5 [7]. Усредненная проба фосфорита содержит (вес. \%): 16,2 $\mathrm{P}_{2} \mathrm{O}_{5} ; 46,2 \mathrm{CaO} ; \mathrm{CaO}: \mathrm{P}_{2} \mathrm{O}_{5}=2,85 ; 17,7 \mathrm{CO}_{2}$; $0,6 \mathrm{MgO} ; 2,9\left(\mathrm{Fe}_{2} \mathrm{O}_{3}+\mathrm{Al}_{2} \mathrm{O}_{3}\right) ; 1,5\left(\mathrm{~K}_{2} \mathrm{O}+\mathrm{Na}_{2} \mathrm{O}\right)$; $2,65 \mathrm{SO}_{3} ; 1,94 \mathrm{~F} ; 7,8$ нерастворимого остатка. Это бедное по фосфору сырьё. Поэтому необходимо его обогащать. Прежде всего, необходимо избавиться от излишнего количества карбонатов. Наиболее распространенный метод обогащения - это флотация. Но Кызылкумские фосфориты наряду с высокой степенью карбонизации, характеризуются прорастанием фосфатного минерала с кальцитом, а попытки обогатить их с помощью флотации не приводит к положительным результатам $[8,9]$.

Поэтому необходимо развивать новые флотационные методы обогащения: находить новые флотореагенты и совершенствовать технику и технологию флотации. Необходим поиск селективных растворителей, которые бы селективно растворяли карбонат кальция и магния в фосфорите, не затрагивая при этом фосфатный минерал [10-15]. Однако эти результаты пока не вышли за рамки лабораторных исследований, только некоторые из них прошли испытания на укрупненных модельных установках.
Естественно, что при таком высоком содержании карбонатов $\left(17,7 \% \mathrm{CO}_{2}\right)$ одним из лучших методов обогащения оказался обжиг. Он и был реализован на Кызылкумском фосфоритовом комплексе в составе комбинированной технологии [16-18], включающей в себя дробление руды, сухое обогащение с получением рядовой фосфоритовой муки, обесшламливание, обжиг для удаления $\mathrm{CO}_{2}$ и промывку сырья от хлора. С 2015 года комплекс ежегодно выпускает 716 тыс. т мытого обожженного концентрата (МОК-26) со средним содержанием $26 \% \mathrm{P}_{2} \mathrm{O}_{5}$.

Следует отметить, что в процессе термического обогащения в качестве промежуточных фосфатных материалов получается фосфоритовая мука (17-18\% $\left.\mathrm{P}_{2} \mathrm{O}_{5}\right)$ и мытый сушеный концентрат (22-24\% $\left.\mathrm{P}_{2} \mathrm{O}_{5}\right)$, а из процесса обогащения выводятся такие отходы, как минерализованная масса $\left(12-14 \% \mathrm{P}_{2} \mathrm{O}_{5}\right)$ и шламовый фосфорит $\left(8-10 \% \mathrm{P}_{2} \mathrm{O}_{5}\right)$, которые пока никак не находят применения в производстве минеральных удобрений. А фосфоритная мука используется для получения простого суперфосфата $\left(12 \% \mathrm{P}_{2} \mathrm{O}_{5}\right)$ на $\mathrm{AO}$ «Навоиазот», «Ферганаазот» и «Кокандский суперфосфатный завод» (ныне «Indorama Kokand Fertilizers and Chemicals»).

Мытый сушеный концентрат (МСК) - это фосфоритная продукция, идущая на получение МОК26 методом обжига при $950-1000{ }^{\circ} \mathrm{C}$. МОК-26 является основным сырьем для производства экстракционной фосфорной кислоты и аммофоса на $\mathrm{AO}$ «Ammofos-Maxam». Необходимо изучить возможность переработки данного сырья в простой суперфосфат.

Цель настоящей работы изучение минералогического состава и физико-механических характеристик МСК и процесса его сернокислотного разложения с получением простого суперфосфата.

\section{Экспериментальная часть}

\section{Характеристика \\ мытого сушеного кониентрата}

Фосфорным веществом в фосфоритах являются минералы апатитовой группы с общей формулой $3 \mathrm{M}_{3}\left(\mathrm{PO}_{4}\right)_{2} \cdot \mathrm{CaX}_{2}$, где М представлен $\mathrm{Ca}^{2+}, \mathrm{a} \mathrm{X}$ - фтором, хлором, группой $\mathrm{OH}, \mathrm{CO}_{3}$. Кальций, входящий в состав фосфатной части молекулы, может изоморфно замещаться стронцием, редкоземельными элементами; ион $\mathrm{PO}_{4}^{3-}$ - ионами $\mathrm{SO}_{4}{ }^{2-}$ и $\mathrm{SiO}_{4}{ }^{2-}$. Наиболее распространен в природе кальцийфторапатит $3 \mathrm{Ca}_{3}\left(\mathrm{PO}_{4}\right)_{2} \cdot \mathrm{CaF}_{2}$ или $\mathrm{Ca}_{5} \mathrm{~F}\left(\mathrm{PO}_{4}\right)_{3}$ и гидроксилапатит $3 \mathrm{Ca}_{3}\left(\mathrm{PO}_{4}\right)_{2} \cdot \mathrm{Ca}(\mathrm{OH})_{2}$ или $\mathrm{Ca}_{5}\left(\mathrm{PO}_{4}\right)_{3} \mathrm{OH}$. Фосфатное вещество фосфоритов кроме фторапатита, может быть представлено, фторкарбонатапати- 
Химическая характеристика различных видов фосфатных минералов

\begin{tabular}{lcccccc}
\hline \multirow{2}{*}{$\begin{array}{c}\text { Тип минералов } \\
\text { апатитовой группы }\end{array}$} & \multirow{2}{*}{ Соединение } & \multicolumn{5}{c}{ Содержание компонентов, вес.\% } \\
\cline { 3 - 6 } Фторапатит & $\mathrm{Pa}_{10} \mathrm{P}_{6} \mathrm{O}_{24} \mathrm{~F}_{2}$ & $\mathbf{C a O}$ & $\mathbf{C O}_{2}$ & $\mathbf{C a F}$ & $\mathbf{C a}(\mathbf{O H})_{2}$ \\
Гидрооксилапатит & $\mathrm{Ca}_{10} \mathrm{P}_{6} \mathrm{O}_{24}(\mathrm{OH})_{2}$ & 42,43 & 50,05 & - & 7,74 & - \\
Карбонатапатит & $\mathrm{Ca}_{10} \mathrm{P}_{6} \mathrm{CO}_{24}(\mathrm{OH})_{3}$ & 35,97 & 48,31 & 4,46 & - & 11,26 \\
Франколит & $\mathrm{Ca}_{10} \mathrm{P}_{5.2} \mathrm{C}_{0.8} \mathrm{O}_{23.2} \mathrm{~F}_{1.8} \mathrm{OH}$ & 37,14 & 48,52 & 3,54 & 7,07 & 3,73 \\
Курскит & $\mathrm{Ca}_{10} \mathrm{P}_{4.8} \mathrm{C}_{1.2} \mathrm{O}_{22.8} \mathrm{~F}_{2}(\mathrm{OH})_{1.2}$ & 34,52 & 47,52 & 5,35 & 7,91 & 4,50 \\
\hline
\end{tabular}

том - франколитом или курскитом. В табл. 1 приведены сравнительный химический и минералогический составы некоторых видов фосфатных минералов [19].

Из неё видно, что наибольшим содержанием фосфора обладает фторапатит, а наименьшим курскит. В структуре курскита имеется ряд отличий от апатита, главное из них состоит в замещении части $\mathrm{PO}_{4}{ }^{3-}$ тетраэдров группами $\mathrm{CO}_{3}{ }^{2-}$. Так, в нём углеродом замещено 20-25\% фосфора апатитовой структуры, в результате теоретическое содержание $\mathrm{P}_{2} \mathrm{O}_{5}$ в нём составляет 33-33,5 \% (при 5,35\% $\mathrm{CO}_{2}$ ). Однако в реальном минерале количество $\mathrm{P}_{2} \mathrm{O}_{5}$ редко превышает 28,5-29\%, что связано с загрязнением фосфатных зёрен тонкодисперсным глауконитом, пиритом, гетитом и органическим веществом. Методами химического, термогравиметрического, ИК-спектроскопического и рентгенографического анализов было установлено, что общая формула курскита по Блисковскому: $\mathrm{Ca}_{10-\mathrm{n} / 2}\left(\mathrm{PO}_{4}\right)_{6-\mathrm{n}}\left(\mathrm{CO}_{3}\right)_{\mathrm{n}} \mathrm{F}_{2}$, где $\mathrm{n}=1,5[20]$.

Фосфатные руды Центральных Кызылкумов, в том числе МСК относятся к зернистым фосфоритам, главным минералом которых является франколит. Он имеет параметры элементарной ячейки $\mathrm{a}_{\mathrm{o}}=9,33 \mathrm{~A}^{\circ}, \mathrm{c}_{\mathrm{o}}=6,89 \mathrm{~A}^{\circ}$ и содержит $37 \% \mathrm{P}_{2} \mathrm{O}_{5}, 3,5 \%$ $\mathrm{CO}_{2}$ и до $3 \% \mathrm{SO}_{3}$, изоморфно входящих в его кристаллическую структуру.

В качестве объекта исследования выбран

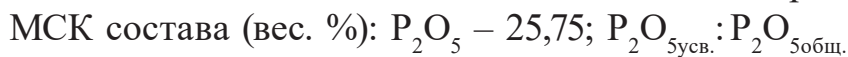
$=13,08 ; \mathrm{CaO}-52,07 ; \mathrm{MgO}-0,30 ; \mathrm{CO}_{2}-10,97$; $\mathrm{Fe}_{2} \mathrm{O}_{3}-0,31 ; \mathrm{Al}_{2} \mathrm{O}_{3}-1,02 ; \mathrm{SO}_{3}-1,48 ; \mathrm{F}-2,76 ; \mathrm{SiO}_{2}$ - 1,78; нерастворимый остаток - 1,$23 ; \mathrm{H}_{2} \mathrm{O}-0,92$; $\mathrm{CaO}_{\text {общ. }}: \mathrm{P}_{2} \mathrm{O}_{\text {5общ. }}=2,02$. Химический анализ сырья на содержание различных компонентов проводили по известным методикам.

Определение $\mathrm{P}_{2} \mathrm{O}_{5}$ проводили дифференциальным способом на приборе КФК-3 (длина волны $\lambda=440$ нм) в виде фосфорнованадиево-молибденового комплекса. $\mathrm{SO}_{3}^{2-}$-ион весовым - осаждением в виде $\mathrm{BaSO}_{4}$. Определение содержания $\mathrm{CaO}$ и $\mathrm{MgO}$ осуществляли объёмным комплексонометрическим методом: титрованием 0,05 н раствором трилона Б в присутствии индикатора флуорексон и хром темно-синий, соответственно. Анализ на $\mathrm{Al}_{2} \mathrm{O}_{3}$ и $\mathrm{Fe}_{2} \mathrm{O}_{3}$ проводили также комплексонометрическим методом титрованием 0,05 н раствором трилона Б в присутствии индикатора ксиленово-оранжевый и сульфосалициловой кислоты, соответственно. Содержание $\mathrm{CO}_{2}$ определено объёмным методом разложением карбонатов разбавленной соляной кислотой. Определение $\mathrm{F}$ проводилось потенциометрическим методом с помощью фторселективного электрода. $\mathrm{SiO}_{2}$ определяли гравиметрическим методом с осаждением кремниевой кислоты с применением желатина, а нерастворимого остатка в царской водке.

Для разработки технологии получения фосфорных удобрений были изучены физико-механические его свойства (дисперсный состав, влажность, насыпная плотность, угол откоса, текучесть, $\mathrm{pH}$, гигроскопичность, влагоёмкость).

\section{Результаты и их обсуждение}

Ситовой анализ показывает, что дисперсность МСК характеризуется следующим образом: класс $(-2+1$ мм $)-1,4 \% ;(-1+0,63$ мм $)-1,9 \% ;(-0,63+$ $0,4$ мм $)-2,4 \% ;(-0,4+0,315$ мм $)-7,0 \% ;(-0,31+$ $0,25$ мм $)-8,3 \% ;(-0,25+0,16$ мм $)-41,1 \% ;(-0,16+$ 0,1 мм) $-26,6 \% ;(-0,1+0,05$ мм $)-8,5 \% ;(-0,05$ мм $)$ $-2,8 \%$. Изучением свойств показано, что при исходной влажности $(0,92 \%)$ свободная насыпная

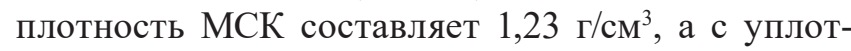
нением составляет 1,56 г $\mathrm{cm}^{3}$. Величина угла естественного откоса равна 28 градусов. Он без всяких затруднений рассевается. Гигроскопическая точка оказалась - 59,2\%, а предельная влагоёмкость $6,2 \%$, но при более высоких влажностях он теряет свою рассыпчатость. В связи с этим при хранении и перевозке необходимо предохранять его от увлажнения. 


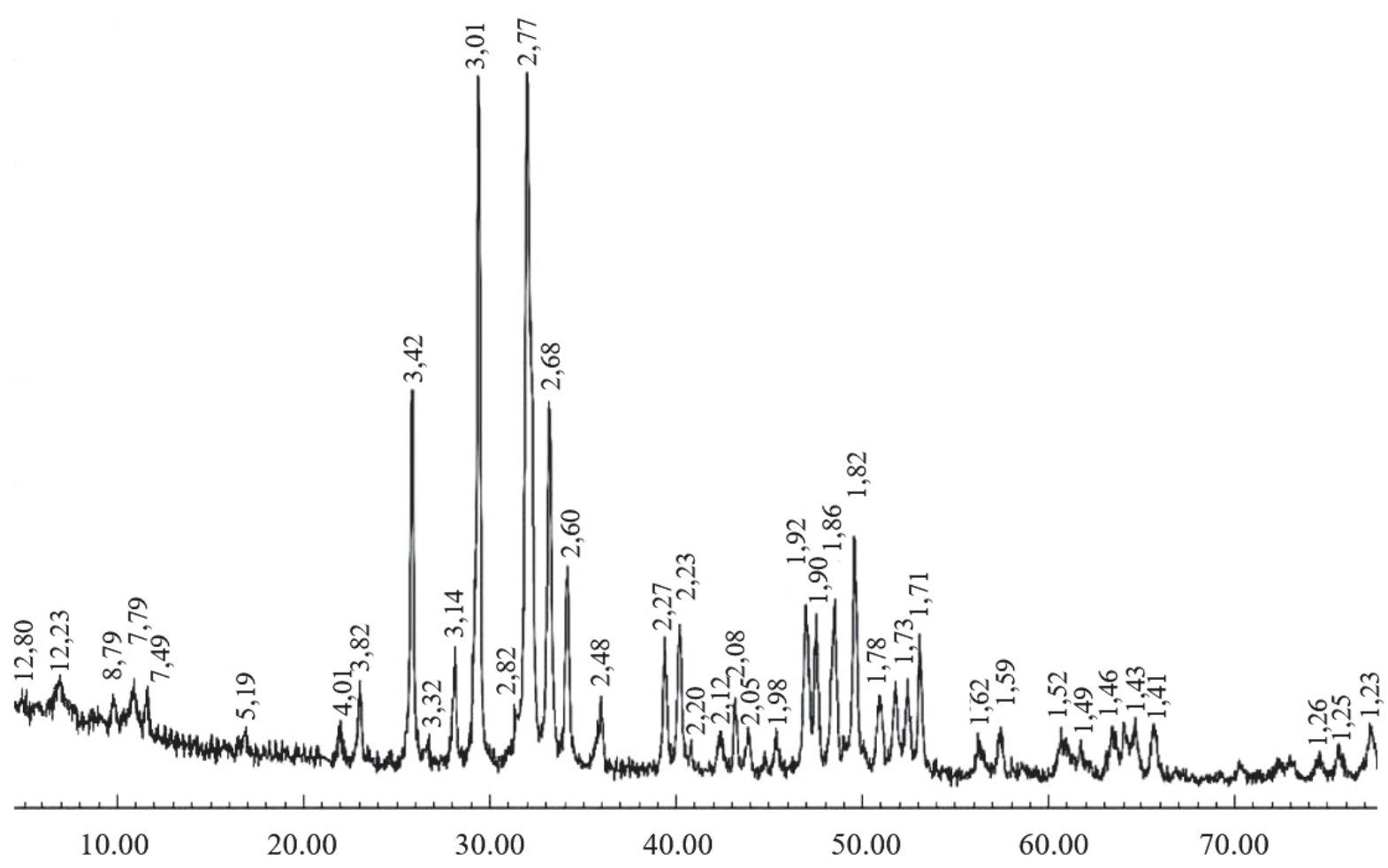

Рис. 1. Рентгенограмма мытого сушеного концентрата

Для ориентировочного определения минералогического состава МСК мы сняли её рентгенограмму на дифрактометре XRD-6100 (Shimadzu, пр-во Япония). Применяли $\mathrm{CuK}_{\alpha}$-излучение ( $\beta$-фильтр, $\mathrm{Ni}$, режим тока и напряжения трубки $30 \mathrm{~mA}, 30 \mathrm{kV}$ ) и постоянную скорость вращения детектора 4 град/мин, а угол сканирования изменялся от 4 до $80^{\circ}$. При снятии образцов применялась камера с вращением, где скорость вращения равна 30 об/мин. Идентификация минеральных фаз производилась с применением базы данных 2013 International Centre for Diffraction Data. Рентгенограмма МСК представлена на рис. 1.

На рентгенограмме дифракционные полосы 3,$43 ; 3,14 ; 2,83 ; 2,77 ; 2,68 ; 2,60 ; 2,23 ; 1,92 ; 1,82 ; 1,75$; 1,$73 ; 1,71 \mathrm{~A}^{\circ}$ принадлежат фторкарбонатапатиту. Наличие кальцита подтверждают межплоскостные расстояния 3,$82 ; 3,01 ; 2,48 ; 2,27 ; 2,08 ; 1,90 \mathrm{~A}^{\circ}$, доломита $-1,78 \mathrm{~A}^{\circ}$. Полосы $3,32 \mathrm{~A}^{\circ}$ свидетельствуют о присутствии кварца, но его очень мало. В меньшем количестве также могут присутствовать полевые шпаты, глауконит, бентонит, хлорит и др.

Химический состав и физико-механические свойства МСК показывают, что это фосфатное сырье вполне пригоден для получения различных марок фосфорсодержащих удобрений.

Для уточнения о наличии количественного содержания указанных минералов нами выполнены расчёты на основе химического состава МСК.
Ниже приведен расчёт по определению содержания минералов фосфатного сырья на 1000 кг.

Расчёт минерального состава мытого сушеного концентрата

Таким образом, зернистые фосфориты Центральных Кызылкумов входят в франколитовую группу апатитовой породы.

Если судить по содержанию фосфора и фтора в франколите, на одну весовую часть $\mathrm{P}_{2} \mathrm{O}_{5}$ приходится примерно 0,09262 весовых частей фтора: $\frac{\mathrm{F}}{P_{2} O_{5}}=\frac{3,44}{37,14}=0,09262 ;$ а в нашем случае этот показатель $\quad$ составляет $\quad \frac{\mathrm{F}}{P_{2} \mathrm{O}_{5}}=\frac{2,76}{25,75}=0,10718$. То есть в этом случае разница незначительна, только $\frac{\mathrm{F}}{\mathrm{P}_{2} \mathrm{O}_{5}}=0,01456$ единицы. Данный факт указывает на то, что в Кызылкумском фосфорите содержится излишний фтор в виде $\mathrm{CaF}_{2}$.

Далее приводятся расчеты на минеральные компоненты франколита МСК с некоторыми дополнениями разниц величин по содержанию компонентов. Значит, расчет выполнен для 1000 кг MCK. 
Химическая формула франколита выглядит следующим образом:

$$
\begin{aligned}
& 2 \mathrm{Ca}_{10} \mathrm{P}_{5,2} \mathrm{C}_{0,8} \mathrm{O}_{23,2} \mathrm{~F}_{1,8} \mathrm{OH} \rightarrow \\
& \rightarrow 5,2 \mathrm{P}_{2} \mathrm{O}_{5}+18,2 \mathrm{CaO}+1,6 \mathrm{CO}_{2}+1,8 \mathrm{CaF}_{2}+\mathrm{H}_{2} \mathrm{O}
\end{aligned}
$$
$M C K$.

\section{I. Распределение компонентов по франколиту}

Сначала по содержанию пятиокиси фосфора в МСК рассчитывается количество франколита, содержащегося в 1-ой тонне МСК:

$$
\mathrm{m}_{\text {(франколит) }}=\frac{2 \cdot 993,2 \cdot 257,5}{5,2 \cdot 142}=692,71 \text { кг }
$$

где: 993,2 - $\mathrm{M}_{(\text {фанколит) }}$, г/моль; 257,5 - количество $\mathrm{P}_{2} \mathrm{O}_{5}$ в 1000 кг МСК, кг; $142-\mathrm{M}\left(\mathrm{P}_{2} \mathrm{O}_{5}\right)$, г/моль.

Теперь, рассчитываем количество $\mathrm{CaO}$, находящегося в франколите:

$$
\mathrm{m}\left(\mathrm{CaO}_{\text {франколит }}\right)=\frac{257,5 \cdot 18,2 \cdot 56}{5,2 \cdot 142}=355,42 \text { кг }
$$

где: $56-\mathrm{M}(\mathrm{CaO})$, г/моль.

Находим количество $\mathrm{CO}_{2}$ в франколите:

$$
\mathrm{m}\left(\mathrm{CO}_{\text {2франколит }}\right)=\frac{257,5 \cdot 1,6 \cdot 44}{5,2 \cdot 142}=24,55 \text { кг }
$$

где: $44-\mathrm{M}\left(\mathrm{CO}_{2}\right)$, г/моль.

$\mathrm{B}$ франколитной структуре содержится $\mathrm{CaF}_{2}$ :

$$
\mathrm{m}\left(\mathrm{CaF}_{\text {2франколит }}\right)=\frac{257,5 \cdot 1,8 \cdot 78}{5,2 \cdot 142}=48,96 \text { кг }
$$

где: $78-\mathrm{M}\left(\mathrm{CaF}_{2}\right)$, г/моль.

Отсюда вычитываем количество $\mathrm{F}$ и $\mathrm{CaO}$, связанных в $\mathrm{CaF}_{2}$ по схеме:

$$
1,8 \mathrm{CaF}_{2} \rightarrow 1,8 \mathrm{CaO}+3,6 \mathrm{~F}^{-}
$$

Сначала находим количество $\mathrm{F}$ в виде $\mathrm{CaF}_{2}$ :

$$
\mathrm{m}\left(F_{\mathrm{CaF}_{2}}\right)=\frac{48,96 \cdot 3,6 \cdot 19}{1,8 \cdot 78}=23,85 \text { кг }
$$

где: $19-\mathrm{M}(\mathrm{F})$, г/моль.

Затем из него рассчитываем количество $\mathrm{CaO}$, связанное в $\mathrm{CaF}_{2}$ :

$$
\mathrm{m}\left(\mathrm{CaO}_{\mathrm{CaF}_{2}}\right)=\frac{23,85 \cdot 1,8 \cdot 56}{3,6 \cdot 19}=35,15 \text { кг }
$$

II. Распределение компонентов по примесным соединениям МСК.

Из вышеприведенного химического состава видно, что в 1-ой тонне МСК содержится 27,6 кг фтора, а из вышеприведенного расчета следует, что в франколитной структуре связано 23,85 кг фтора. Значит, $27,6-23,85=3,75$ кг фтора в свободном состоянии находятся в виде $\mathrm{CaF}_{2} \rightarrow \mathrm{CaO}+2 \mathrm{~F}^{-}$.
Поэтому находим количество $\mathrm{CaO}$, связанное в $\mathrm{CaF}_{2}$ в $\mathrm{MCK}$ :

$$
\mathrm{m}\left(\mathrm{CaO}_{\mathrm{CaF}_{2}}\right)=\frac{3,75 \cdot 56}{2 \cdot 19}=5,526 \text { кг }
$$

Оно эквивалентно $\mathrm{CaF}_{2}$ :

$$
\mathrm{m}\left(\mathrm{CaF}_{2}\right)=\frac{5,526 \cdot 78}{56}=7,696 \text { кг }
$$

Определим количество доломита $-\mathrm{CaMg}\left(\mathrm{CO}_{3}\right)_{2}$ в МСК:

$$
\mathrm{m}_{\text {(доломит) }}=\frac{3 \cdot 184}{40}=13,8 \text { кг }
$$

где: 3,0 - количество $\mathrm{MgO}$ в 1000 кг МСК, кг; $184-\mathrm{M}\left(\mathrm{CaMg}\left(\mathrm{CO}_{3}\right)_{2}\right)$, г/моль; $40-\mathrm{M}(\mathrm{MgO})$, г/моль.

В доломите присутствует $\mathrm{CaO}$, связанное в доломите:

$$
\mathrm{MgCO}_{3} \cdot \mathrm{CaCO}_{3} \rightarrow \mathrm{MgO}+\mathrm{CaO}+2 \mathrm{CO}_{2}:
$$

Находим количество $\mathrm{CaO}$ в доломите:

$$
\mathrm{m}\left(\mathrm{CaO}_{\text {доломит }}\right)=\frac{3 \cdot 56}{40}=4,2 \text { кг }
$$

где: $56-\mathrm{M}(\mathrm{CaO})$, г/моль; $40-\mathrm{M}(\mathrm{MgO})$, г/моль.

Находим количество $\mathrm{CO}_{2}$ в доломите:

$$
\mathrm{m}\left(\mathrm{CO}_{\text {2доломит }}\right)=\frac{2 \cdot 3 \cdot 44}{40}=6,6 \text { кГ }
$$

где: $44-\mathrm{M}\left(\mathrm{CO}_{2}\right)$, гомоль.

По результатам аналитических данных, общее количество $\mathrm{CO}_{2}$ в 1-ой тонне МСК составляет 109,7 кг.

Из вышеприведенных расчетов следует, что карбонат ангидрид находится в МСК в виде следующих минералов:

$$
\begin{aligned}
& \mathrm{m}\left(\mathrm{CO}_{2 \text { фосфорит }}\right)-\left(\mathrm{m}\left(\mathrm{CO}_{\text {2франколит }}\right)+\mathrm{m}\left(\mathrm{CO}_{\text {2доломит }}\right)\right)= \\
& =\mathrm{m}\left(\mathrm{CO}_{\text {2кальцит }}\right)
\end{aligned}
$$

Значит, $109,7-(24,55+6,6)=78,55$ кг $\mathrm{CO}_{2}$ связано в минерале кальците:

$$
\mathrm{CaCO}_{3} \rightarrow \mathrm{CaO}+\mathrm{CO}_{2}
$$

Из него находим количество $\mathrm{CaCO}_{3}$ в $\mathrm{MCK}$ :

$$
\mathrm{m}_{\text {(кальцит) }}=\frac{78,55 \cdot 100}{44}=178,52 \text { кг }
$$

где: $100-\mathrm{M}\left(\mathrm{CaCO}_{3}\right)$.

Находим количество $\mathrm{CaO}$ в кальците:

$$
\mathrm{m}\left(\mathrm{CaO}_{\text {кальцит }}\right)=\frac{78,55 \cdot 56}{44}=99,97 \text { кг }
$$


Находим количество пассивного $\mathrm{CaO}$ в МСК. Он представлен в виде гипса: $\mathrm{CaO}+\mathrm{SO}_{3} \rightarrow \mathrm{CaSO}_{4}$

Находим количество $\mathrm{CaO}$ в гипсе:

$$
\mathrm{m}\left(_{\text {СаОгипг }}\right)=\frac{14,8 \cdot 56}{80}=10,36 \text { кг }
$$

где: 14,8 - количество $\mathrm{SO}_{3}$ в 1000 кг МСК, кг; $80-\mathrm{M}\left(\mathrm{SO}_{3}\right)$, г/моль.

Отсюда рассчитываем количество гипса:

$$
\left.\mathrm{m}_{\text {гипс }}\right)=\frac{10,36 \cdot 172}{56}=31,82 \text { кг }
$$

где: $172-\mathrm{M}\left(\mathrm{CaSO}_{4} 2 \mathrm{H}_{2} \mathrm{O}\right)$, г/моль.

Теперь определим общее количество $\mathrm{CaO}$ в МСК, как в активной (реакционноспособной), так и в пассивной (нереакционноспособной) формах:

К реакционноспособным (активным) формам $\mathrm{CaO}$ относятся:

$$
\begin{aligned}
& \mathrm{m}(\mathrm{CaO})=\mathrm{m}\left(\mathrm{CaO}_{\text {франколит }}\right)+\mathrm{m}\left(\mathrm{CaOCaF}_{\text {2франколит }}\right)+ \\
& +\mathrm{m}\left(\mathrm{CaOCaF}_{2}\right)+\mathrm{m}\left(\mathrm{CaO}_{\text {доломит }}\right)+\mathrm{m}_{\left(\mathrm{CaO}_{\text {кальцит }}\right)=}= \\
& =355,42+35,15+5,526+4,2+99,97=500,266 \text { кг }
\end{aligned}
$$

А к нереакционноспособным (пассивным) $\mathrm{CaO}$ относится:

$$
\mathrm{m}\left(_{\text {СаОгипс }}\right)=10,36 \text { кг }
$$

По результатам аналитических данных, общее количество $\mathrm{CaO}$ в 1-ой тонне МСК составляет 520,7 кг. Значит, оставшееся количество $\mathrm{CaO}$ составляет:

$$
\mathrm{m}(\mathrm{CaO})=520,7-500,266-10,36=10,074 \text { кг }
$$

Оставшийся 10,074 кг $\mathrm{CaO}$ находится в виде силиката кальция:

$$
\mathrm{Ca}_{2} \mathrm{SiO}_{4} \rightarrow 2 \mathrm{CaO}+\mathrm{SiO}_{2}
$$

Находим количество $\mathrm{SiO}_{2}$ в силикате кальция:

$$
\mathrm{m}\left(\mathrm{SiO}_{2}\right) \frac{10,074 \cdot 60}{2 \cdot 56}=5,396 \text { кг }
$$

где: $60-\mathrm{M}\left(\mathrm{SiO}_{2}\right)$, г/моль.

Отсюда рассчитываем количество силиката кальция $\left(\mathrm{Ca}_{2} \mathrm{SiO}_{4}\right)$ :

$$
\mathrm{m}\left(\mathrm{Ca}_{2} \mathrm{SiO}_{4}\right) \frac{10,074 \cdot 172}{2 \cdot 56}=15,48 \text { кг }
$$

где: $172-\mathrm{M}\left(\mathrm{Ca}_{2} \mathrm{SiO}_{4}\right)$, г/моль; $56-\mathrm{M}(\mathrm{CaO})$, г/моль.

На основе полученных данных составлена табл. 2, отражающая минеральный состав МСК.

Таким образом, мытый сушеный концентрат относится к зернистым типам, главным минералом которых является франколит. Из него вполне можно получить простой суперфосфат для местного применения.

\section{Изучение прочесса двухстадийной переработки мытого сушеного концентрата в простой} cynepфосфат

Кокандский суперфосфатный завод в Узбекистане производит простой аммонизированный суперфосфат камерным способом [21]. Этот метод включает стадии: разложение фосфоритовой муки (17-18\% $\left.\mathrm{P}_{2} \mathrm{O}_{5}\right)$ серной кислотой концентрацией $60 \%$ при её норме $100 \%$ и $70-75^{\circ} \mathrm{C}$; камерное вызревание суперфосфатной массы в течение $1-1,5$ ч при $115-120^{\circ} \mathrm{C}$; складское дозревание в течение 6 суток при 3-х разовом перелопачивании; грануляцию и аммонизацию, сушку и рассев продукта. При этом готовый продукт содержит $12 \%$ $\mathrm{P}_{2} \mathrm{O}_{\text {5общ. }}, 1,5 \% \mathrm{~N}, \mathrm{P}_{2} \mathrm{O}_{\text {รводн. }}: \mathrm{P}_{2} \mathrm{O}_{\text {5общ. }}=50 \%$ и прочностью гранул 1,5 МПа.

Недостатки камерной (классической) технологии производства простого суперфосфата, следующие:

a) шестисуточное дозревание на складе и трехкратное перелопачивание, пассивация активных

Минералогический состав мытого сушеного концентрата

\begin{tabular}{lccc}
\hline \multicolumn{1}{c}{$\begin{array}{c}\text { Минеральные составляющие } \\
\text { фоссырья }\end{array}$} & Количество, вес.\% & $\begin{array}{c}\text { Минеральные составляющие } \\
\text { фоссырья }\end{array}$ & $\begin{array}{c}\text { Количество, } \\
\text { вес.\% }\end{array}$ \\
\hline $\mathrm{Ca}_{10} \mathrm{P}_{5,2} \mathrm{C}_{0,8} \mathrm{O}_{23,2} \mathrm{~F}_{1,8} \mathrm{OH}$ & 69,27 & $\mathrm{CaF}_{2}$ & 0,77 \\
$\mathrm{CaCO}_{3}$ & 17,85 & $\mathrm{Al}_{2} \mathrm{O}_{3}$ & 1,02 \\
$\mathrm{CaMg}\left(\mathrm{CO}_{3}\right)_{2}$ & 1,38 & $\mathrm{Fe}_{2} \mathrm{O}_{3}$ & 0,31 \\
$\mathrm{CaSO}_{4} \cdot 2 \mathrm{H}_{2} \mathrm{O}$ & 3,18 & Нерастворимый остаток & 1,23 \\
\hline $\mathrm{SiO}_{2}$ & 1,24 & $\mathrm{~K}_{2} \mathrm{O}+\mathrm{Na}_{2} \mathrm{O}$ & 0,1 \\
$\mathrm{Ca}_{2} \mathrm{SiO}_{4}$ & 1,55 & (глауконит и орг.в-ва) & \\
\hline $\mathrm{H}_{2} \mathrm{O}$ & 0,92 & Прочие & $<1,18$ \\
\hline
\end{tabular}


центров всего расходуемого фторкарбонатаратита и недозавершение экстракции $\mathrm{H}_{3} \mathrm{PO}_{4}$ в жидкую фазу;

б) диффузионное торможение реакции образования $\mathrm{Ca}\left(\mathrm{H}_{2} \mathrm{PO}_{4}\right)_{2}$ и высокое содержание свободной $\mathrm{H}_{3} \mathrm{PO}_{4}$ в камерном продукте;

c) неудовлетворительное гранулирование суперфосфатной массы и высокая ретурность;

d) неорганизованный выброс вредных веществ и высокая запыленность производственных помещений, так как складское дозревание является мощным источником выброса фтористых соединений в атмосферу.

Столь длительный процесс разложения фосфатного сырья объясняется тем, что при реакции с $\mathrm{H}_{2} \mathrm{SO}_{4}$ на поверхности зерен фосфорита образуется поверхностная корка из кристаллов $\mathrm{CaSO}_{4}$ [22]. $\mathrm{B}$ ходе реакции с $\mathrm{H}_{3} \mathrm{PO}_{4}$ образуется ещё один слой из кристаллов фосфата кальция. Таким образом, как в серной, так и в фосфорной кислотах необходимо преодолеть слой осевших на поверхности зерен кристаллов, чтобы вступить в реакцию с самим зерном фосфата. Лимитирующей стадией процесса разложения, как для апатита, так и для фосфорита является процесс диффузии [23]. То есть на стадиях камерного и складского дозревания лимитирующей стадией процесса является скорость диффузии кислоты сквозь образовавшуюся солевую корку [24].

В работе [25] проведен анализ условий труда рабочих, основных профессий, занятых в производстве суперфосфата. При этом на рабочих местах зарегистрированы превышение предельно допустимых концентраций промышленных аэрозолей, ухудшение параметров микроклимата, превышение показателей уровня вибрации. При общей гигиенической оценке классов условий труда машиниста-скрепера и машиниста-перегружателя соответствует 3-ему вредному 2-ой степени; машиниста-крана и расфасовка-упаковочных машин, аппаратчика - 3-ему вредному 3 -ей степени.

Суть предлагаемого способа. Особенностью предлагаемого нами способа получения гранулированного суперфосфата из карбонатных фосфоритов по сравнению с классической является то, что технологический процесс также осуществляется в две стадии:

1) Основная часть (70-80\% от общей массы) фосфорита разлагается 92-93\%-ной $\mathrm{H}_{2} \mathrm{SO}_{4}$, взятой при 100-105 \% нормах от стехиометрии для образования 45-50 \%-ной $\mathrm{P}_{2} \mathrm{O}_{5}$ фосфорной кислоты, где сульфат кальция кристаллизуется в виде ангидрита;

2) Полученная на первой стадии кислая реакционная масса, содержащая концентрированную фосфорную кислоту (45-50 \% $\mathrm{P}_{2} \mathrm{O}_{5}$ ) и ангидрит об- рабатывается оставшейся частью (20-30 \%) фосфорита, в результате чего происходит процесс нейтрализации фосфорной кислоты на монокальцийфосфат.

Продолжительность первой стадии сернокислотного разложения составляет 15-20 минут при $120-130{ }^{\circ} \mathrm{C}$. А процессы нейтрализации кислой массы и гранулирование продукта окатыванием совмещены в одном аппарате. Продолжительность 25-30 минут. Следует отметить, что из схемы исключается стадия сушки продукта.

Для выяснения механизма разложения фосфатного сырья в двух стадиях поставлено настоящее исследование.

Расчет нормы расхода серной кислоты для обработки мытого сушеного концентрата в ангидридном режиме с образованием фосфорной кислоты на первой стадии и нейтрализации свободной фосфорной кислоты мытым сушеным концентратом с образованием монокальцийфосфата на второй стадии.

I-я стадия обработки прочесса получения простого суперфосфата (полное разложение мытого сушеного кониентрата с образованием фосфорной кислоты в ангидридном режиме).

В основе образования фосфорной кислоты лежит реакция серной кислоты с франколитом:

$$
\begin{aligned}
& \mathrm{Ca}_{10} \mathrm{P}_{5,2} \mathrm{C}_{0,8} \mathrm{O}_{23,2} \mathrm{~F}_{1,8} \mathrm{OH}+10 \mathrm{H}_{2} \mathrm{SO}_{4} \rightarrow \\
& \rightarrow 5,2 \mathrm{H}_{3} \mathrm{PO}_{4}+10 \mathrm{CaSO}_{4}+0,8 \mathrm{CO}_{2}+1,8 \mathrm{HF}+1,8 \mathrm{H}_{2} \mathrm{O}
\end{aligned}
$$

Рассчитываем расход серной кислоты для разложения франколита с образованием фосфорной кислоты:

$$
\mathrm{m}^{1}\left(\mathrm{H}_{2} \mathrm{SO}_{4}\right)=\frac{692,71 \cdot 10 \cdot 98}{993,2}=683,50 \text { кг }
$$

где: 692,71 - количество франколита в 1000 кг МCK, кг; 98 - $\left.\mathrm{M}_{(2} \mathrm{H}_{2} \mathrm{SO}_{4}\right)$, г/моль; 993,2 - $\mathrm{M}_{\text {(франколит)' }}$ г/моль.

Расход серной кислоты для разложения $\mathrm{CaF}_{2}$ по реакции: $\mathrm{CaF}_{2}+\mathrm{H}_{2} \mathrm{SO}_{4}=\mathrm{CaSO}_{4}+2 \mathrm{HF} \uparrow$

$$
\mathrm{m}^{2}\left(\mathrm{H}_{2} \mathrm{SO}_{4}\right)=\frac{5,52 \cdot 98}{56}=9,67 \text { кг }
$$

где: 5,52 - масса $\mathrm{CaF}_{2}$ в 1000 кг МСК, кг; 56 $\mathrm{M}(\mathrm{CaO})$, гомоль.

Следует отметить, что часть $\mathrm{CaO}$ связано c $\mathrm{MgO}$ в виде доломита $\left(\mathrm{MgCO}_{3} \times \mathrm{CaCO}_{3}\right)$.

Расход серной кислоты для разложения $\mathrm{CaO}$ в доломите по реакции:

$$
\mathrm{CaCO}_{3}+\mathrm{H}_{2} \mathrm{SO}_{4}=\mathrm{CaSO}_{4}+\mathrm{CO}_{2} \uparrow
$$




$$
\mathrm{m}^{3}\left(\mathrm{H}_{2} \mathrm{SO}_{4}\right)=\frac{4,2 \cdot 98}{56}=7,35 \text { кг }
$$

где: 4,2 - количество $\mathrm{CaO}$ из доломита в 1000 кг МСК, кг; $56-\mathrm{M}(\mathrm{CaO})$, г/моль.

Расход серной кислоты для разложения $\mathrm{MgO}$ по реакции: $\mathrm{MgCO}_{3}+\mathrm{H}_{2} \mathrm{SO}_{4}=\mathrm{MgSO}_{4}+\mathrm{CO}_{2} \uparrow$

$$
\mathrm{m}^{4}\left(\mathrm{H}_{2} \mathrm{SO}_{4}\right)=\frac{3 \cdot 98}{40}=7,35 \mathrm{\kappa \Gamma}
$$

где: 3,0 - количество $\mathrm{MgO}$ из доломита в 1000 кг МСК, кг; 40 - M(MgO), г/моль.

Расход серной кислоты для разложения кальцит $\left(\mathrm{CaCO}_{3}\right)$ в МСК по реакции: $\mathrm{CaCO}_{3}+$ $\mathrm{H}_{2} \mathrm{SO}_{4}=\mathrm{CaSO}_{4}+\mathrm{CO}_{2} \uparrow$

$$
\mathrm{m}^{5}\left(\mathrm{H}_{2} \mathrm{SO}_{4}\right)=\frac{99,97 \cdot 98}{56}=174,94 \text { кг }
$$

где: 99,97 - количество $\mathrm{CaO}$ из кальцита в 1000 кг МСК, кг; $56-\mathrm{M}(\mathrm{CaO})$, г/моль.

Расход серной кислоты для разложения силиката кальция по реакции:

$$
\begin{aligned}
& \mathrm{Ca}_{2} \mathrm{SiO}_{4}+2 \mathrm{H}_{2} \mathrm{SO}_{4} \rightarrow 2 \mathrm{CaSO}_{4}+\mathrm{SiO}_{2}+2 \mathrm{H}_{2} \mathrm{O} \\
& \mathrm{m}^{6}\left(\mathrm{H}_{2} \mathrm{SO}_{4}\right)=\frac{15,48 \cdot 2 \cdot 98}{172}=17,64 \text { кг }
\end{aligned}
$$

где: 15,48 - количество $\mathrm{Ca}_{2} \mathrm{SiO}_{4}$ в 1000 кг МСК, кг; $172-\mathrm{M}\left(\mathrm{Ca}_{2} \mathrm{SiO}_{4}\right)$, г/моль.

Рассчитываем расход серной кислоты для разложения оксида железа (III) по реакции:

$$
\begin{aligned}
& \mathrm{Fe}_{2} \mathrm{O}_{3}+3 \mathrm{H}_{2} \mathrm{SO}_{4} \rightarrow \mathrm{Fe}_{2}\left(\mathrm{SO}_{4}\right)_{3}+3 \mathrm{H}_{2} \mathrm{O} \\
& \mathrm{m}^{7}\left(\mathrm{H}_{2} \mathrm{SO}_{4}\right)=\frac{3,1 \cdot 3 \cdot 98}{160}=5,69 \text { кг }
\end{aligned}
$$

где: 3,1 - количество $\mathrm{Fe}_{2} \mathrm{O}_{3}$ в 1000 кг МСК, кг; $160-\mathrm{M}\left(\mathrm{Fe}_{2} \mathrm{O}_{3}\right)$, г/моль.

Рассчитываем расход серной кислоты для разложения оксида алюминия (III) по реакции:

$$
\begin{aligned}
& \mathrm{Al}_{2} \mathrm{O}_{3}+3 \mathrm{H}_{2} \mathrm{SO}_{4} \rightarrow \mathrm{Al}_{2}\left(\mathrm{SO}_{4}\right)_{3}+3 \mathrm{H}_{2} \mathrm{O} \\
& \mathrm{m}^{8}\left(\mathrm{H}_{2} \mathrm{SO}_{4}\right)=\frac{10,2 \cdot 3 \cdot 98}{102}=29,4 \text { к }
\end{aligned}
$$

где: 10,2 - количество $\mathrm{A}_{2} \mathrm{O}_{3}$ в 1000 кг МСК, кг; $102-\mathrm{M}\left(\mathrm{Al}_{2} \mathrm{O}_{3}\right)$, г моль.

Таким образом, на 1-стадии образования фосфорной кислоты суммарный расход $100 \%$-ной серной кислоты для разложения кислоторазлагаемых компонентов МСК составляет:

$\sum \mathrm{H}_{2} \mathrm{SO}_{4}=683,5\left(\mathrm{~m}^{1}\right)+9,67\left(\mathrm{~m}^{2}\right)+7,35\left(\mathrm{~m}^{3}\right)+$

$+7,35\left(\mathrm{~m}^{4}\right)+174,94\left(\mathrm{~m}^{5}\right)+17,64\left(\mathrm{~m}^{6}\right)+5,69\left(\mathrm{~m}^{7}\right)+$

$+29,4\left(\mathrm{~m}^{8}\right)=935,54$ кг
Или в пересчете на $93 \%$-ной $\mathrm{H}_{2} \mathrm{SO}_{4}$ :

$$
\mathrm{m}\left(93 \% \mathrm{H}_{2} \mathrm{SO}_{4}\right)=\frac{935,54}{0,93}=1005,95 \text { кг }
$$

$\mathrm{Ca}_{10} \mathrm{P}_{5,2} \mathrm{C}_{0,8} \mathrm{O}_{23,2} \mathrm{~F}_{1,8} \mathrm{OH}+10 \mathrm{H}_{2} \mathrm{SO}_{4} \rightarrow 5,2 \mathrm{H}_{3} \mathrm{PO}_{4}+$ $10 \mathrm{CaSO}_{4}+1,8 \mathrm{H}_{2} \mathrm{O}+0,8 \mathrm{CO}_{2}+1,8 \mathrm{HF}$

Таким образом, при $100 \%$-ном сернокислотном разложении 1000 кг мытого сушеного концентрата (с содержанием $25,75 \% \mathrm{P}_{2} \mathrm{O}_{5}$ ) образуется фосфорная кислота $\left(100 \% \mathrm{H}_{3} \mathrm{PO}_{4}\right)$ в количестве:

$$
\mathrm{m}\left(100 \% \mathrm{H}_{3} P_{4}\right)=\frac{257,5 \cdot 5,2 \cdot 98}{2,6 \cdot 142}=355,42 \text { кг }
$$

II-я стадия обработки прочесса получения простого суперфосфата (нейтрализация фосфорной кислоты с мытым сушеным концентратом для образования монокальцийфосфата).

Основная реакция разложения франколита с фосфорной кислотой:

$$
\begin{aligned}
& \mathrm{Ca}_{10} \mathrm{P}_{5,2} \mathrm{C}_{0,8} \mathrm{O}_{23,2} \mathrm{~F}_{1,8} \mathrm{OH}+14,8 \mathrm{H}_{3} \mathrm{PO}_{4}+8,2 \mathrm{H}_{2} \mathrm{O} \rightarrow \\
& \rightarrow 10 \mathrm{Ca}\left(\mathrm{H}_{2} \mathrm{PO}_{4}\right)_{2}+1,8 \mathrm{HF}+0,8 \mathrm{CO}_{2}
\end{aligned}
$$

Рассчитываем расход фосфорной кислоты для разложения франколита с образованием монокальцийфосфата:

$$
\mathrm{m}^{1}\left(H_{3} P_{4}\right)=\frac{692,71 \cdot 14,8 \cdot 98}{993,2}=1011,585 \text { кг }
$$

где: 692,71 - количество франколита в 1000 кг МСК, кг; 98 - $\mathrm{M}\left(\mathrm{H}_{3} \mathrm{PO}_{4}\right)$, г/моль; 993,2 - $\mathrm{M}_{\text {(франколит) }}$, г/моль.

Фосфорная кислота для разложения $\mathrm{CaO}_{\text {акти }}$ во фториде и силикате кальция, кальците и доломите расходуется по реакции:

$$
\begin{aligned}
& \mathrm{Ca}_{2} \mathrm{SiO}_{4}+4 \mathrm{H}_{3} \mathrm{PO}_{4} \rightarrow 2 \mathrm{Ca}\left(\mathrm{H}_{2} \mathrm{PO}_{4}\right)_{2} \cdot \mathrm{H}_{2} \mathrm{O}+\mathrm{SiO}_{2} \\
& \mathrm{CaO}+2 \mathrm{H}_{3} \mathrm{PO}_{4} \rightarrow \mathrm{Ca}\left(\mathrm{H}_{2} \mathrm{PO}_{4}\right)_{2} \cdot \mathrm{H}_{2} \mathrm{O} \\
& \mathrm{CaF}_{2}+2 \mathrm{H}_{3} \mathrm{PO}_{4} \rightarrow \mathrm{Ca}\left(\mathrm{H}_{2} \mathrm{PO}_{4}\right)_{2} \cdot \mathrm{H}_{2} \mathrm{O}+2 \mathrm{HF}
\end{aligned}
$$

Суммарное количество активного оксида кальция в МСК составляет:

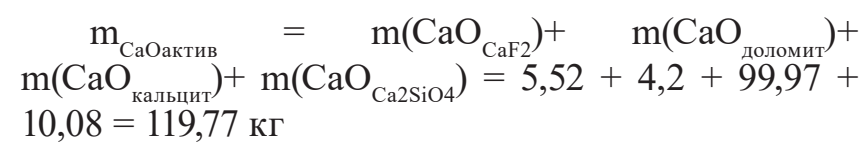

где: 5,$52 ; 4,2 ; 99,97$ и 10,08 - количество $\mathrm{CaF}_{2}$; $\mathrm{CaO}_{\text {доломит }} ; \mathrm{CaO}_{\text {кальцит }}$ и $\mathrm{CaO}_{\mathrm{Ca} 2 \mathrm{SiO} 4}$ в 1000 кг МСК, кг; Рассчитываем суммарный расход фосфорной кислоты для разложения активного $\mathrm{CaO}$ в МСК:

$$
\mathrm{m}^{2}\left(H_{3} P_{4}\right)=\frac{119,77 \cdot 2 \cdot 98}{56}=419,2 \text { кг }
$$


Для разложения $\mathrm{MgO}$ в доломите расходуется $\mathrm{H}_{3} \mathrm{PO}_{4}$ по реакции: $\mathrm{MgO}+\mathrm{H}_{3} \mathrm{PO}_{4}=\mathrm{MgHPO}_{4}+\mathrm{H}_{2} \mathrm{O}$

$$
\mathrm{m}^{3}\left(H_{3} P O_{4}\right)=\frac{3 \cdot 98}{40}=7,35 \text { кг }
$$

где: 3 - количество $\mathrm{MgO}$ в 1000 кг МСК, кг; $40-\mathrm{M}(\mathrm{MgO})$, г/моль.

Расход $\mathrm{H}_{3} \mathrm{PO}_{4}$ на разложение полуторных окислов в МСК:

$$
\begin{aligned}
& \mathrm{Fe}_{2} \mathrm{O}_{3}+2 \mathrm{H}_{3} \mathrm{PO}_{4} \rightarrow 2 \mathrm{FePO}_{4}+3 \mathrm{H}_{2} \mathrm{O} \\
& \mathrm{m}^{4}\left(H_{3} \mathrm{PO}_{4}\right)=\frac{3,1 \cdot 2 \cdot 98}{160}=3,80 \text { Кг }
\end{aligned}
$$

где: 3,1 - количество $\mathrm{Fe}_{2} \mathrm{O}_{3}$ в 1000 кг МСК, кг; 160 $\mathrm{M}\left(\mathrm{Fe}_{2} \mathrm{O}_{3}\right)$, г/моль.

$$
\begin{aligned}
& \mathrm{Al}_{2} \mathrm{O}_{3}+2 \mathrm{H}_{3} \mathrm{PO}_{4} \rightarrow 2{\mathrm{~A} 1 \mathrm{PO}_{4}+3 \mathrm{H}_{2} \mathrm{O}}^{5} \mathrm{~m}^{5}\left(H_{3} P O_{4}\right)=\frac{10,2 \cdot 2 \cdot 98}{102}=19,6 \text { кг }
\end{aligned}
$$

где: 10,2 - количество $\mathrm{A}_{2} \mathrm{O}_{3}$ в 1000 кг МСК, кг; $102-\mathrm{M}\left(\mathrm{Al}_{2} \mathrm{O}_{3}\right)$, г/моль.

При расчете 100 \%-ного разложения 1000 кг МСК суммарный расход фосфорной кислоты на различные компоненты составляет: $\mathrm{m}_{\text {нзРО4 }}=1011,585\left(\mathrm{~m}^{1}\right)+419,195\left(\mathrm{~m}^{2}\right)+7,35\left(\mathrm{~m}^{3}\right)+$ $3,80\left(\mathrm{~m}^{4}\right)+19,6\left(\mathrm{~m}^{5}\right)=1461,52 \kappa \Gamma$

Таким образом, на I-ой стадии сернокислотного разложения 1000 кг МСК образуется $\mathrm{m}_{\text {нзРО4(100 \%) }}=355,42$ кг $100 \%$-ной фосфорной кислоты.

Тогда, рассчитывается количество МСК (100\% от стехиометрии реакций), необходимое для нейтрализации 355,42 кг фосфорной кислоты с обра- зованием монокальцийфосфата во II-ой стадии переработки при получении простого суперфосфата:

$$
\mathrm{M}_{\mathrm{MCK}}=\frac{355,42 \cdot 1000}{1461,52}=243,19 \text { кг }
$$

где: 355,42 - количество $100 \%$-ной $\mathrm{H}_{3} \mathrm{PO}_{4}$, образующейся при $100 \%$-ном сернокислотном разложении 1000 кг МСК, кг; 1461,52 - количество $100 \%$-ной $\mathrm{H}_{3} \mathrm{PO}_{4}$, необходимой для разложения 1000 кг МСК, кг.

\section{Прочесс получения простого суперфосфата}

Опыты по разложению МСК серной кислотой проводили в термостатированном реакторе, снабженном лопастной мешалкой при $130{ }^{\circ} \mathrm{C}$ (Необходимую для поддерживания ангидридного режима за счет тепла реакции). Норму серной кислоты брали $100 \%$ от стехиометрии на образование $\mathrm{H}_{3} \mathrm{PO}_{4}$ с учетом вышеуказанных реакций разложения примесных компонентов фосфатного сырья (І-ая стадия переработки). Содержание $\mathrm{P}_{2} \mathrm{O}_{\text {รсвоб. }}$ в реакционных массах и готовых продуктах определяли титрованием 0,1 н $\mathrm{NaOH}$ с применением индикаторов метилоранжа и фенолфталеина.

Сначала изучили кинетику разложения фосфатного сырья. При этом время контактирования компонентов был 2; 5; 10; 20; 40 и 60 минут. Результаты представлены на рис. 2 и 3.

Из неё видно, что с увеличением продолжительности взаимодействия с 2 до 20 минут коэффициент разложения МСК серной кислотой повышается, то есть относительное содержание водорас-

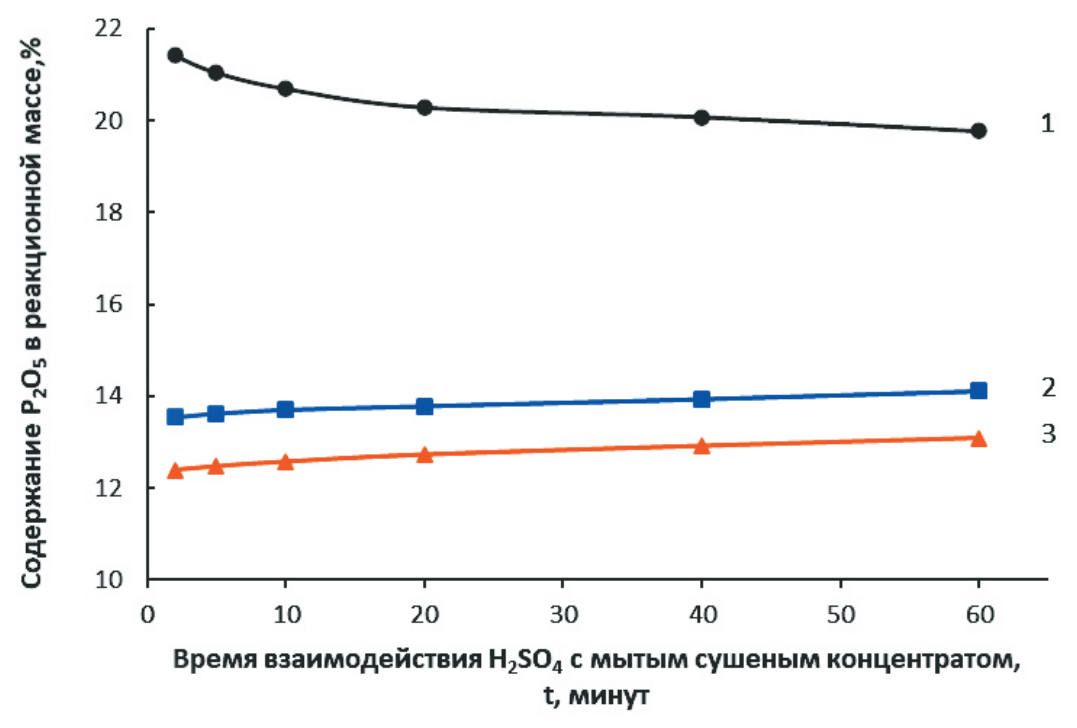

Рис. 2. Содержание свободной кислотности, общей и водной формы $\mathrm{P}_{2} \mathrm{O}_{5}$ в кислой суперфосфатной массе в зависимости от времени контактирования мытого сушеного концентрата серной кислотой 1 - свободная кислотность; 2 - общей $\mathrm{P}_{2} \mathrm{O}_{5} ; 3-$ водный $\mathrm{P}_{2} \mathrm{O}_{5}$ 


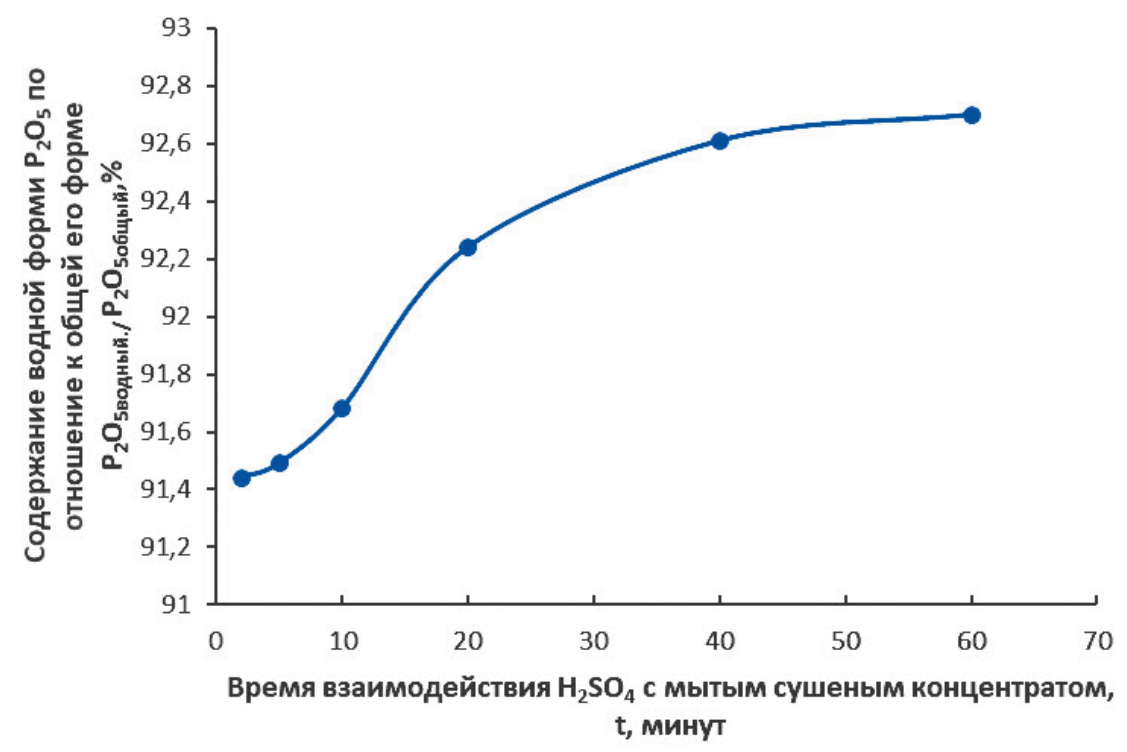

Рис. 3. Содержание относительной формы $\mathrm{P}_{2} \mathrm{O}_{5}$ по отношению к общему его содержанию в зависимости от времени контактирования мытого сушеного концентрата серной кислотой

творимой формы $\mathrm{P}_{2} \mathrm{O}_{5}$ по отношению к общей его форме с 91,44 до 92,24 \%. Дальнейшее увеличение времени с 40 до 60 минут этот показатель повышается незначительно, только с 92,61 до 92,7 \%. При этом в реакционной массе общее содержание $\mathrm{P}_{2} \mathrm{O}_{5}$ повышается с 13,55 до 14,11 \%, а свободная кислотность, наоборот, снижается с 21,42 до 19,77 \%. Наибольшая концентрация свободной кислотности объясняется тем, что в реакционной массе кроме фосфорной кислоты присутствуют непрореагировавшая $\mathrm{H}_{2} \mathrm{SO}_{4}$, а также $\mathrm{H}_{2} \mathrm{SiF}_{6}$ и $\mathrm{HF}$, образующиеся в процессе разложения.

Из данных можно делать вывод о том, что с технологической точки зрения, время разложения фосфатного сырья достаточно 20-30 минут. Дальнейшее увеличение времени не приводит к существенному повышению коэффициенту разложения. А при продолжительности обработки менее 20-30 минут не происходит достаточное образование тиксотропной массы, необходимой для дальнейшей обработки реакционной массы.

Во втором этапе выполнены опыты по получению готового суперфосфата путем нейтрализации кислой реакционной массы с МСК (вторая стадия обработки). При этом норму МСК варьировали от 100 до $270 \%$ от стехиометрии на образование монокальцийфосфата (II-ая стадия переработки). При этом суммарная норма $\mathrm{H}_{2} \mathrm{SO}_{4}$ (включительно 1-ой и 2-стадий разложения фосфатного сырья) составляет от 79 до 105 \% на образование монокальцийфосфата с учетом вышеуказанных реакций разложения примесных компонен- тов. Время нейтрализации реакционной массы 20 минут при $130{ }^{\circ} \mathrm{C}$. Реакция нейтрализации кислой массы с МСК на второй стадии процесса фактически является началом процесса гранулирования, где в роли центра гранулирования выступает насыщенный фосфорной кислотой каркас из кристалликов сульфата кальция. Грануляцию нейтрализованного продукта осуществляли методом окатывания. Полученный по предлагаемому способу гранулированный продукт отличается низкой дисперсностью, а гранулы имеют высокую сопротивляемость к динамическому истиранию.

В готовых продуктах усвояемую форму $\mathrm{P}_{2} \mathrm{O}_{5}$ определяли по растворимости в $2 \%$-ной лимонной кислоте. Результаты химического анализа приведены в табл. 3.

Из таблицы видно, что чем выше нормы МСК, тем ниже содержание $\mathrm{P}_{2} \mathrm{O}_{5 \text { своб. }}$ и тем выше $\mathrm{P}_{2} \mathrm{O}_{\text {5обш. }}$ в суперфосфате. Так, если при норме МСК - $100 \%$ (общая норма $\mathrm{H}_{2} \mathrm{SO}_{4}-105 \%$ ) от стехиометрии на об-

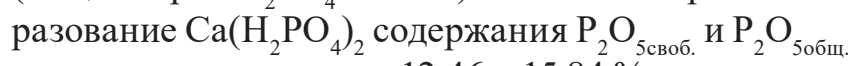
в продукте составляют 12,46 и $15,84 \%$, то при норме МСК - $200 \%$ (общая норма $\mathrm{H}_{2} \mathrm{SO}_{4}-88 \%$ ) эти показатели имеют 6,60 и $17,17 \%$, при норме МСК $240 \%$ (общая норма $\mathrm{H}_{2} \mathrm{SO}_{4}-83 \%$ ) - 4,50 и $17,28 \%$, а при норме МСК - $270 \%$ (общая норма $\mathrm{H}_{2} \mathrm{SO}_{4}$ -

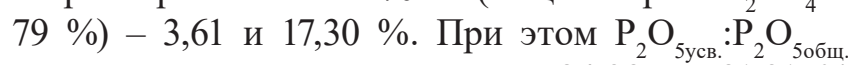
и $\mathrm{P}_{2} \mathrm{O}_{\text {5водн. }}: \mathrm{P}_{2} \mathrm{O}_{\text {5обш. }}$ снижаются с 84,28 до $81,21 \%$ и с 84,09 до $68,32 \%$, соответственно.

В таблице приведен также состав высушенных образцов простого суперфосфата. Согласно регламенту, в готовом суперфосфате содержа- 
Состав продуктов после нейтрализации и сушки суперфосфатной массы (исходная норма 93 \%-ной $\mathrm{H}_{2} \mathrm{SO}_{4}-100$ \% от стехиометрии на образование $\mathrm{H}_{3} \mathrm{PO}_{4}$ )

\begin{tabular}{|c|c|c|c|c|c|c|c|}
\hline \multirow{2}{*}{$\begin{array}{c}\text { Норма МСК } \\
\text { на образование } \\
\text { Са( }\left(\mathrm{H}_{2} \mathrm{PO}_{4}\right)_{2} \\
\%\end{array}$} & \multirow{2}{*}{$\begin{array}{l}\text { Исходная норма } \\
\mathrm{H}_{2} \mathrm{SO}_{4} \text { (для I-ой } \\
\text { и II-ой стадии) } \\
\text { на образование } \\
\mathrm{Ca}\left(\mathrm{H}_{2} \mathrm{PO}_{4}\right)_{2}, \%\end{array}$} & \multicolumn{4}{|c|}{ Содержание $\mathrm{P}_{2} \mathrm{O}_{5}$ в реакционной массе, вес. \% } & \multirow[b]{2}{*}{$\begin{array}{c}\mathbf{P}_{2} \mathbf{O}_{\text {5усвв }}: \\
\mathbf{P}_{2} \mathbf{O}_{\text {5общ. }} \%\end{array}$} & \multirow[b]{2}{*}{$\begin{array}{l}\mathbf{P}_{2} \mathbf{O}_{\text {5водн. }}: \\
\mathbf{P}_{2} \mathbf{O}_{\text {5обш. }} \%\end{array}$} \\
\hline & & $\mathbf{P}_{2} \mathbf{O}_{\text {5об̆щ. }}$ & $\mathbf{P}_{2} \mathbf{O}_{\text {5усв. }}$ & $\mathbf{P}_{2} \mathbf{O}_{\text {Бводн. }}$ & $\mathbf{P}_{2} \mathbf{O}_{\text {5своб. }}$ & & \\
\hline \multicolumn{8}{|c|}{ После нейтрализации кислой реакционной массы с мытым сушеным концентратом } \\
\hline 100 & 105 & 15,84 & 13,35 & 13,32 & 12,46 & 84,28 & 84,09 \\
\hline 180 & 91 & 16,76 & 13,79 & 12,76 & 8,00 & 82,28 & 76,13 \\
\hline 200 & 88 & 17,17 & 13,97 & 12,60 & 6,60 & 81,36 & 73,38 \\
\hline 220 & 85 & 17,27 & 14,05 & 12,25 & 5,46 & 81,35 & 70,93 \\
\hline 240 & 83 & 17,28 & 14,05 & 11,85 & 4,50 & 81,30 & 68,57 \\
\hline 260 & 80 & 17,29 & 14,05 & 11,83 & 3,87 & 81,26 & 68,42 \\
\hline 270 & 79 & 17,30 & 14,05 & 11,82 & 3,61 & 81,21 & 68,32 \\
\hline \multicolumn{8}{|c|}{ После сушки влажного простого суперфосфата } \\
\hline 180 & 91 & 16,86 & 14,03 & 12,68 & 7,08 & 83,21 & 75,20 \\
\hline 200 & 88 & 17,27 & 14,09 & 12,46 & 5,60 & 81,58 & 72,14 \\
\hline 220 & 85 & 17,37 & 14,17 & 12,25 & 4,86 & 81,57 & 70,52 \\
\hline 240 & 83 & 17,38 & 14,17 & 12,22 & 4,15 & 81,53 & 70,31 \\
\hline 260 & 80 & 17,39 & 14,17 & 12,19 & 3,56 & 81,48 & 70,09 \\
\hline 270 & 79 & 17,40 & 14,17 & 12,18 & 3,50 & 81,43 & 70,00 \\
\hline
\end{tabular}

ние $\mathrm{P}_{2} \mathrm{O}_{5 \text { своб. }}$ не должно превышать $5 \%$. Исходя из этого, при $220 \%$-ной норме МСК (общая норма $\mathrm{H}_{2} \mathrm{SO}_{4}-85 \%$ ) состав сухого продукта выгля-

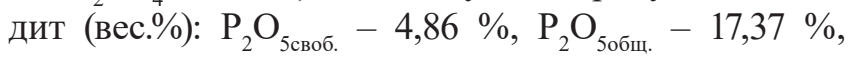
$\mathrm{P}_{2} \mathrm{O}_{\text {5усв. }}: \mathrm{P}_{2} \mathrm{O}_{\text {5общ. }}=81,57 \%$ и $\mathrm{P}_{2} \mathrm{O}_{\text {5водн. }}: \mathrm{P}_{2} \mathrm{O}_{\text {5общ. }}=70,52 \%$, а его прочность гранул составляет 1,99 МПа.

\section{Выводы}

Определен минеральный состав зернистого фосфорита - мытого сушеного концентрата методами химического и рентгенографического анализа. Результаты показывают, что основным минералом фосфатного сырья является франколит, а в качестве примесей присутствуют кальцит, доломит, силикат и фторид кальция, гипс, кремний, полуторные окислы и др.

Рассчитана норма серной кислоты для получения из него простого суперфосфата путем двухстадийного разложения мытого сушеного концентрата, на первой стадии которого фосфатное сырье обрабатывается стехиометрическим расходом $93 \%$-ной серной кислоты и при $130^{\circ} \mathrm{C}$ в условиях полного разложения с образованием фосфорной кислоты и ангидрита (сульфата кальция), а во второй образовавшийся концентрированный раствор фосфорной кислоты участвует в реакции с дополнительным количеством фосфатного сырья, что является основой механизма химического образования монокальцийфосфата и гранулирование суперфосфатной массы и где исключаются стадии аммонизации и сушки готового продукта.

Таким образом, предлагаемый способ потребляет меньше энергоресурсов, как за счёт использования энергосберегающего оборудования, так и исключения из её состава схемы энергоемких стадий процесса, таких как складское дозревание и сушка. К тому же исключается ввод извне нейтрализующих агентов (известковая мука, жидкий или газообразный аммиак и др.) и связующих добавок (фосфорная кислота, фосфатные и сульфатные соли аммония и др.).

\section{Литература}

1. Цыкин Р.A. Journal of Siberian Federal University. Engineering\&Technologies. 2010. №3. P. 135-146.

2. Фосфор - «элемент жизни», его возрастающая роль для человечества. Фосфаты на рубеже XXI века. Москва-Алматы-Жанатас: 1996. 108 с. 
3. Хохлов А.В. География мировой фосфатной промышленности. http://docplayer.ru/30402127-Geografiyamirovoy-fosfatnoy-promyshlennosti.html, 2001.

4. Беглов Б.М., Намазов Ш.С. Фосфориты Центральных Кызылкумов и их переработка. Ташкент: ФАН. 2013. $460 \mathrm{c}$.

5. Ангелова М.А. Химическая промышленность. 1997. №2. C. 92-97.

6. Фосфаты в XXI веке. - Алматы, Тараз, Жанатас, 2006, $201 \mathrm{c}$.

7. Дехканов 3.К., Намазов Ш.С., Сейтназаров А.Р. Беглов Б.М. Узбекский химический журнал. 2016. №3. C. $70-80$.

8. Абдурахманов С.А., Аскаров М.А., Донияров Н.А., Амонов Х.У. Горный вестник Узбекистана. 2002. № 1. C. 44-45.

9. Аскаров М.А., Донияров Н.А., Нуркулова Е.А. Горный вестник Узбекистана. 2005. №3. С. 87-89.

10. Sultonov B.S., Namazov Sh.S., Zakirov B.S. Journal of Chemical Technology and Metallurgy. 2015. V. 50. N 1. P. 26-34.

11. Gharabaghi M., Irannajad M., Noaparast M. Hydrometallurgy. 2010. N 103. P. 96-107.

12. Seitnazarov A., Namazov Sh., Beglov B. Journal of Chemical Technology and Metallurgy. 2014. V. 49. N 4. P. 383-390.

13. Zafar Z.I., Ashraf M. Chemical Engineering Journal. 2007. N 131. P. 41-48.

14. Zafar Z.I., Anwar M.M., Pritchard D.W. Minerals Engineering. 2006. V. 19. N 14. P. 1459-1461.

15. Lukomona C., Mwalula J.B., Witika L.K. African Journal of Science and Technology (AJST). Science and Engineering Series. 2005. N 2. P. 113-119.

16. Кучерский Н.И., Толстов Е.А., Михин О.А., Мазуркевич А.П., Иноземцев С.Б., Соколов В.Д., Смирнов Ю.М. Горная промышленность. 2001. № 4. С. 48-51.

17. Исмагилов М.M. Кызылкумский фосфоритовый комплекс Навоийского ГМК. Матер. респ. науч.техн. конф. «Актуальные проблемы химической переработки фосфоритов Центральных Кызылкумов». 23 ноября 2006 года. Ташкент: 2006. С. 19-22.

18. Цезарь Норберт В. Обогащение полезных ископаемых. 2008. № 1. С.10-15.

19. Отабоев Х., Раджабов Р., Шеркузиев Д., Намазов Ш., Бадалова О., Сейтназаров А. Минералогический состав фосфоритовой муки Центральных Кызылкумов. XVI-International Correspondence Scientific Specialized Conference «International Scientific Review Of The Technical Sciences, Mathematics And Computer Science» (Boston. Usa. July 12-13, 2020). P. 80-89.

20. Usmanov Kh., Chernyakova R., Dzhusipbekov U. Perspectives of Innovations. Economics\&Business. 2010. V. 6. Is. 3. P. 135-137.

21. Таджиев С.М., Беглов Б.М. Химическая промышленность. 2002. № 7. С. 7-10.

22. Ангелов А.И., Соболев Н.В. Успехи в химии и химической технологии. 2003. T. XVII. № 8. С. 39-41.

23. Сахаров Ю.Н., Махоткин А.Ф., Махоткин И.А., Ситкин А.И. Вестник Казанского технологического университета. 2011. № 11. С. 18-22.
24. Самоедов М.М., Оруджев С.С., Самоедова Т.А. Химическая промышленность сегодня. 2005. №8. C. 19-22.

25. Байдюк О.Н., Липатов Г.Я., Стяжкина Е.С. Фундаментальные исследования. 2010. № 7. С. 13-16.

\section{References}

1. Tsykin R.A. Phosphorites and apatite raw materials of Central Siberia. Journal of Siberian Federal University. Engineering\&Technologies. 2010. N. 3. P. 135-146. (in Russian)

2. Phosphorus is an "element of life", its growing role for humanity. Phosphates at the turn of the 21 st century. Moscow-Almaty-Zhanatas: 1996.108 p. (in Russian)

3. Khokhlov A.V. Geography of the world phosphate industry. http://docplayer.ru/30402127-Geografiya-mirovoyfosfatnoy-promyshlennosti.html. 2001. (in Russian)

4. Beglov B.M, Namazov Sh.S. Phosphorites of Central Kyzyl Kum and their processing. Tashkent: FAN. 2013.460 p. (in Russian)

5. Angelova M.A. Production and consumption of phosphate raw materials in the USA. Khimich. promyshlennost. 1997. N. 2. P. 92-97. (in Russian)

6. Phosphates in the XXI century. - Almaty, Taraz, Zhanatas. 2006. 201 p. (in Russian)

7. Dekhkanov Z.K., Namazov Sh.S., Seitnazarov A.R. Beglov B.M. Phosphorites of Central Kyzyl Kum and their concentration. Uzbekskiy chimicheskiy journal. 2016. N. 3. P. 70-80. (in Russian)

8. Abdurakhmanov S.A., Askarov M.A., Doniyarov N.A., Amonov Kh.U. Study of flotation concentration of phosphorite ore in the Dzheroy-Sardarya deposit. Gorniy vestnik Uzbekistana. 2002. N. 1. P. 44-45. (in Russian)

9. Askarov M.A., Doniyarov N.A., Nurkulova E.A. Flotation of phosphorite ores. Gorniy vestnik Uzbekistana. 2005. N. 3. P. 87-89. (in Russian)

10. Sultonov B.S., Namazov Sh.S., Zakirov B.S. Investigation of nitric acid benefication of low grade phosphorites from Central Kyzylkum. Journal of Chemical Technology and Metallurgy. 2015. V. 50. N 1. P. 26-34.

11. Mahdi Gharabaghi, Mehdi Irannajad, Mohammad Noaparast. A review of the beneficiation of calcareous phosphate ores using organic acid leaching. Hydrometallurgy. 2010. N. 103. P. 96-107.

12. Seitnazarov A., Namazov Sh., Beglov B. Beneficiation of high-calcareous phosphorites of Central Kyzylkum with organic acid solutions. Journal of Chemical Technology and Metallurgy. 2014. V. 49. N 4. P. 383-390.

13. Zafar Z.I., Ashraf M. Selective leaching kinetics of calcareous phosphate rock in lactic acid. Chemical Engineering Journal. 2007. N. 131. P. 41-48.

14. Zafar Z.I., Anwar M.M., Pritchard D.W. Selective leaching of calcareous phosphate rock in formic acid: optimization of operating conditions. Minerals Engineering. 2006. V. 19. N. 14. P. 1459-1461.

15. Lukomona C., Mwalula J.B., Witika L.K. The beneficiation of Mumbwa phosphate deposit by various techniques. African Journal of Science and Technology 
(AJST). Science and Engineering Series. 2005. N. 2. P. 113-119.

16. Kuchersky N.I., Tolstov E.A., Mikhin O.A., Mazurkevich A.P., Inozemtsev S.B., Sokolov V.D., Smirnov Yu.M. Combined technology for beneficiation of granular phosphorites. Gornaya promyshlennost. 2001. N. 4. P. 48-51. (in Russian)

17. Ismagilov M.M. Kyzylkum phosphorite complex of Navoi MMC. Mater. rep. scientific and technical conf. "Actual problems of chemical processing of phosphorites of the Central Kyzyl Kum". November 23, 2006. Tashkent: 2006. P. 19-22. (in Russian)

18. Tsezar Norbert $V$. Industrial removal of chlorides from phosphate ore in the wet process of concentration in the extreme conditions of the Uzbek desert. Obagasheniye poleznykh iskopaemykh. 2008. N. 1. P.10-15. (in Russian) (in Russian)

19. Otaboev H., Radjabov R., Sherkuziev D., Namazov Sh., Badalova O., Seytnazarov A. Mineralogical composition of phosphorite flour of the Central Kyzyl Kum. XVI-International Correspondence Scientific Specialized Conference "International Scientific Review Of The Technical Sciences, Mathematics And Computer Science" (Boston. Usa. July 12-13, 2020). P. 80-89. (in Russian)
20. Usmanov Kh., Chernyakova R., Dzhusipbekov U. Influence of modifying additives on the properties of dispersed phosphorites. Perspectives of Innovations. Economics \& Business. 2010. V. 6. Iss. 3. P. 135-137. (in Russian)

21. Tadzhiev S.M., Beglov B.M. Development of technology for simple ammoniated superphosphate from Tashkur phosphorites by the chamber method. Khimich. promyshlennost. 2002. N. 7. P. 7-10. (in Russian)

22. Angelov A.I., Sobolev N.V. Development of technology for enriched superphosphate from phosphate rock of the Yegoryevskoye field. Uspekhi v khimii i khimich. Tekhnologii. 2003. V. XVII. N. 8. P. 39-41. (in Russian)

23. Sakharov Yu.N., Makhotkin A.F., Makhotkin I.A., Sitkin A.I. Mechanism and kinetics of decomposition of phosphate raw materials. Bulletin of Kazan Technological University. 2011. N. 11. S. 18-22. (in Russian)

24. Samoyedov M.M., Orudzhev S.S., Samoyedova T.A. Intensification and mathematical description of the superphosphate production process. Khimich. Promyshlennost segodnya. 2005. N. 8. P.19-22. (in Russian)

25. Baydyuk O.N., Lipatov G.Ya., Styazhkina E.S. Hygienic characteristics of the factors of the working environment in the production of superphosphates. Fundamentalnye issledovaniya. 2010. N. 7. P. 13-16. (in Russian) 